\title{
Evaluation of cardioprotection and bio- efficacy enhancement of stevioside and diltiazem in rats
}

\author{
Laxit Bhatt ${ }^{1,2^{*}}$, Jay Amrutia ${ }^{2}$, Manodeep Chakraborty ${ }^{2}$ and Jagadish Kamath ${ }^{2}$
}

\begin{abstract}
Background: Cardiovascular diseases and resultant complications of cardio-therapeutic regimens are one of the leading causes of mortalities in developing countries. Diltiazem is a calcium channel blocker primarily used in treatment of supraventricular arrhythmias, systemic hypertension, and hypertrophic cardiomyopathy. Stevioside, the chief component of Stevia plant, is a natural sweetener that has significant therapeutic properties. Stevioside is a known bioenhancer that acts by synergizing pharmacological activities of other drugs. Present study was designed to evaluate cardioprotective activity of stevioside and possible bioenhancement upon co-administration with diltiazem. Standard cardiotoxicity models-isoproterenol-induced myocardial infarction and ischemia-reperfusion injury (IRI) through modified Langendorff setup was used to test this hypothesis. Rats were randomly divided into control groups (normal-physiological saline and toxic_-isoproterenol, $150 \mathrm{mg} / \mathrm{kg}$, s.c., and IRI induced in normal control animals) and treatment groups (diltiazem-17.5 mg/kg, p.o., stevioside-100 and $200 \mathrm{mg} / \mathrm{kg}$, p.o. and combination groups). At the end of the treatment period, animals were sacrificed and biochemical, electrocardiographic, and histopathological changes were measured.

Results: Pre-treatment with stevioside prevented leakage of biomarkers and normalized serum and perfusate levels of CK-MB, CK-NAC, LDH, AST, and ALT enzymes. It displayed lipid-lowering effect on TC and TG levels dose dependently. STV also showed protective action on levels of tissue antioxidant enzymes (SOD and Catalase), electrocardiographic parameters (HR, RR, QRS, QT, PR), and heart tissue histopathology when compared to concurrent toxic control groups. Combination of stevioside $(200 \mathrm{mg} / \mathrm{kg})$ and diltiazem $(17.5 \mathrm{mg} / \mathrm{kg})$ exerted a more significant pharmacodynamic response, significantly restored biomarkers, antioxidants levels, and myocardial histology, and normalized electrocardiographic parameters.

Conclusion: Stevioside and diltiazem both displayed cardioprotective effect when given alone. Co-administration displayed improved restorative action on antioxidant status, biomarkers, electrocardiographic parameters, and histology.
\end{abstract}

Keywords: Ischemia, Myocardial infarction, Phytoconstituents, Cardioprotection, Bioenhancement

\footnotetext{
*Correspondence: bkltox@gmail.com

'Department of Pharmacology and Toxicology, Zydus Research Centre, Ahmedabad, India

2Department of Pharmacology, Shree Devi College of Pharmacy, Mangalore, India
} 


\section{Background}

According to the findings of the National Vital Statistics Report [1] and the Morbidity and Mortality Weekly of the Centers for Disease Control and Prevention [2], cardiovascular diseases including myocardial infarction (MI) and the resultant complications in cardiac function represent the leading cause of morbidity and mortality in developed countries. Moreover, with advances in lifestyle in developing countries, MI is making an increasingly important contribution to the mortality statistics [3]. In spite of the remarkable development of modern medicine in pathological conditions such as cardiovascular disorders, appearance of drug-related toxicity, and lesser potency provoke the need of some alternative therapy [4-6].

Isolated phytoconstituents have demonstrated promising results in treating and preventing various diseases. These herbal constituents reportedly possess potency and safety profile similar to those of synthetic compounds or sometimes even better [7]. Therapists have been trying to meet the challenges of treating diseases by introducing combination therapies, which can potentially restore normal conditions by acting through different mechanisms [8]. Therapeutically potential components when interacting with each other, may mimic, magnify, or oppose the action of each other. Isolated active phytoconstituents have been increasingly combined with standard therapeutic drugs for better efficacy and safety profile [8].

Practitioners worldwide, use stevioside (STV) as an additive, a sweetening agent, and a therapeutic drug. STV is a glycoside isolated from plant Stevia rebaudiana, belonging to family Asteraceae. Extract of stevia leaves is used as a food additive by the Japanese and Brazilians and as a non-caloric sweetener. Stevia rebaudiana contains eight stevia glycosides, responsible for most of its pharmacological activities. Among all, STV is found to be present in the highest concentrations of 5$10 \%$ weight by dried leaves [9]. Along with sweetening properties, STV possess significant pharmacological activities. STV has potent hypotensive effects on dogs and on hypertensive rats without any adverse effects on heart rate or catecholamine levels $[10,11]$. Studies conducted on 60 hypertensive patients showed that treatment with STV significantly decreased blood pressure [12]. It is reported that the mechanism of the hypotensive effect of STV is due to the inhibition of calcium influx via blockage of calcium channels, inhibition of extracellular calcium influx, and release of prostaglandins [13].

STV exerts anti-inflammatory and immunomodulatory action by actively attenuating the nuclear factor (NF)kappa B pathway: inhibition of NF- $\mathrm{kB}$-dependent TNF- $\alpha$ and IL-1 $\beta$ synthesis in LPS-stimulated monocytes [14]. At doses of $25 \mathrm{mg} / \mathrm{kg} /$ day, STV is anti-hyperglycemic primarily due to its insulinotropic and glucagonostic property [15]. STV mediates changes in gluconeogenesis and glycogenolysis by inhibiting the secretion of glucagon from $\alpha$-cells of the pancreas [9]. STV is reported to have better reactive oxygen species scavenging ability than mannitol and sucrose, which attenuates cellular stress [16].

Diltiazem (DTZ) is a non-dihydropyridine, calcium channel blocker, used in the treatment of hypertension, angina pectoris, and some types of arrhythmia [17]. The pharmacological profile of DTZ includes interference of calcium channels and blockage of influx of intracellular calcium: essential for smooth muscle contraction. By blocking calcium channels, DTZ causes relaxation of blood vessels and reduces preload and afterload. It increases the blood flow to the coronary artery by vasodilatation and blocks the atrioventricular (A-V) conductance that results in reduced cardiac workload. DTZ is associated with side effects such as hypotension [18], flushing due to vasodilatation [19], sinus bradycardia [20], and headaches [21]. Severe adverse effects include heart failure and atrial fibrillation when administered with intravenous $\beta$-adrenergic blockers [21].

To alleviate adverse effects related to DTZ, we hypothesized a combination of DTZ and STV and checked its effectiveness against standard models of cardiac injuryisoproterenol (ISO)-induced myocardial infarction and ischemia-reperfusion injury (IRI) in rats. Additionally, there are no studies conducted on evaluation of protective action of STV against ischemic and oxidative stressinduced cardiotoxicity.

This work was the subject of a poster presented at the 9th RBF International Symposium, Ahmedabad, India, 68 Feb 2020.

\section{Methods \\ Animals}

All experimental protocols involving animals were conducted according to the principles stated in the Guide for the Care and Use of Laboratory Animals and guidelines provided by the Committee for the Purpose of Control and Supervision of Experiments on Animals (CPCSEA), the Ministry of Social Justices and Empowerment, Government of India. Institutional Animal Ethics Committee approved the experimental protocol. Female Wistar rats weighing between 200 and $300 \mathrm{~g}$ and approximately of 7-9 weeks of age were selected for the study. Rats were maintained in an animal house with standard facilities. Animals were housed in clean cages with paddy husk bedding and maintained at $25 \pm 5^{\circ} \mathrm{C}$ under 12-h light-dark cycles, and were fed with standard feed with free access to purified drinking water. Animals were acclimatized to laboratory conditions for at least 1 week before starting the experiment. 


\section{Chemicals and reagents}

Pure stevioside was procured from Yucca Enterprises, Mumbai, India. Diltiazem was procured from Torrent Pharmaceuticals Ltd., Ahmedabad, India. Commercial kits for estimation of biomarkers were procured from SPAN Diagnostics, Sachin, India (CK-MB, CK-NAC), Accurex Biomedical Pvt. Ltd., Mumbai, India (LDH) and Robonik India Pvt. Ltd., Thane, India (AST, ALT, TG, $\mathrm{TC})$. Other chemicals and reagents were of the highest analytical grade.

\section{Acute toxicity}

The dose selection of STV was based on an acute toxicity study carried out according to OPPTS (Office of Prevention of Pesticide and Toxic Substance) guidelines following the limit test procedure. STV was dissolved in distilled water and used for the experiment. The animals were fasted overnight prior to the study. Mice were divided into two groups of six each. Test doses of $2 \mathrm{~g} / \mathrm{kg}$ body weight and $5 \mathrm{~g} / \mathrm{kg}$ body weight were administered orally to either group of mice. Mice were observed for $72 \mathrm{~h}$ for mortality.

\section{Isoproterenol-induced myocardial infarction}

After the end of 7 days of acclimatization period, animals were randomized into seven groups $(n=8)$ as following:
- Group I (normal control): served as normal control and received physiological saline for 7 days.

- Group II (ISO control): served as toxic control and received ISO (150 mg $/ \mathrm{kg}$, s.c.) at the end of the treatment period for two consecutive days [22].

- Group III (DTZ): received DTZ (17.5 mg/kg, p.o. [23]) for 7 days and subjected to ISO toxicity at the end of the treatment period for 2 days.

- Group IV (STV 100): received a low dose of STV (100 mg/kg, p.o.) for 7 days and subjected to ISO toxicity at the end of the treatment period for 2 days.

- Group V (STV 200): received a high dose of STV ( $200 \mathrm{mg} / \mathrm{kg}$, p.o.) for 7 days and subjected to ISO toxicity at the end of the treatment period for 2 days.

- Group VI (STV 100 + DTZ): received a low dose of STV (100 mg/kg, p.o.) along with DTZ (17.5 mg/kg, p.o.) for 7 days and subjected to ISO toxicity at the end of the treatment period for 2 days.

- Group VII (STV 200 + DTZ): received a high dose of STV (200 mg $/ \mathrm{kg}$, p.o.) along with DTZ (17.5 mg/ $\mathrm{kg}$, p.o.) for 7 days and subjected to ISO toxicity at the end of the treatment period for 2 days.

Forty-eight hours after the first dose of ISO, the animals were anesthetized with ketamine $(70 \mathrm{mg} / \mathrm{kg}$, i.p.) and xylazine $(10 \mathrm{mg} / \mathrm{kg}$, i.p.), and blood was withdrawn

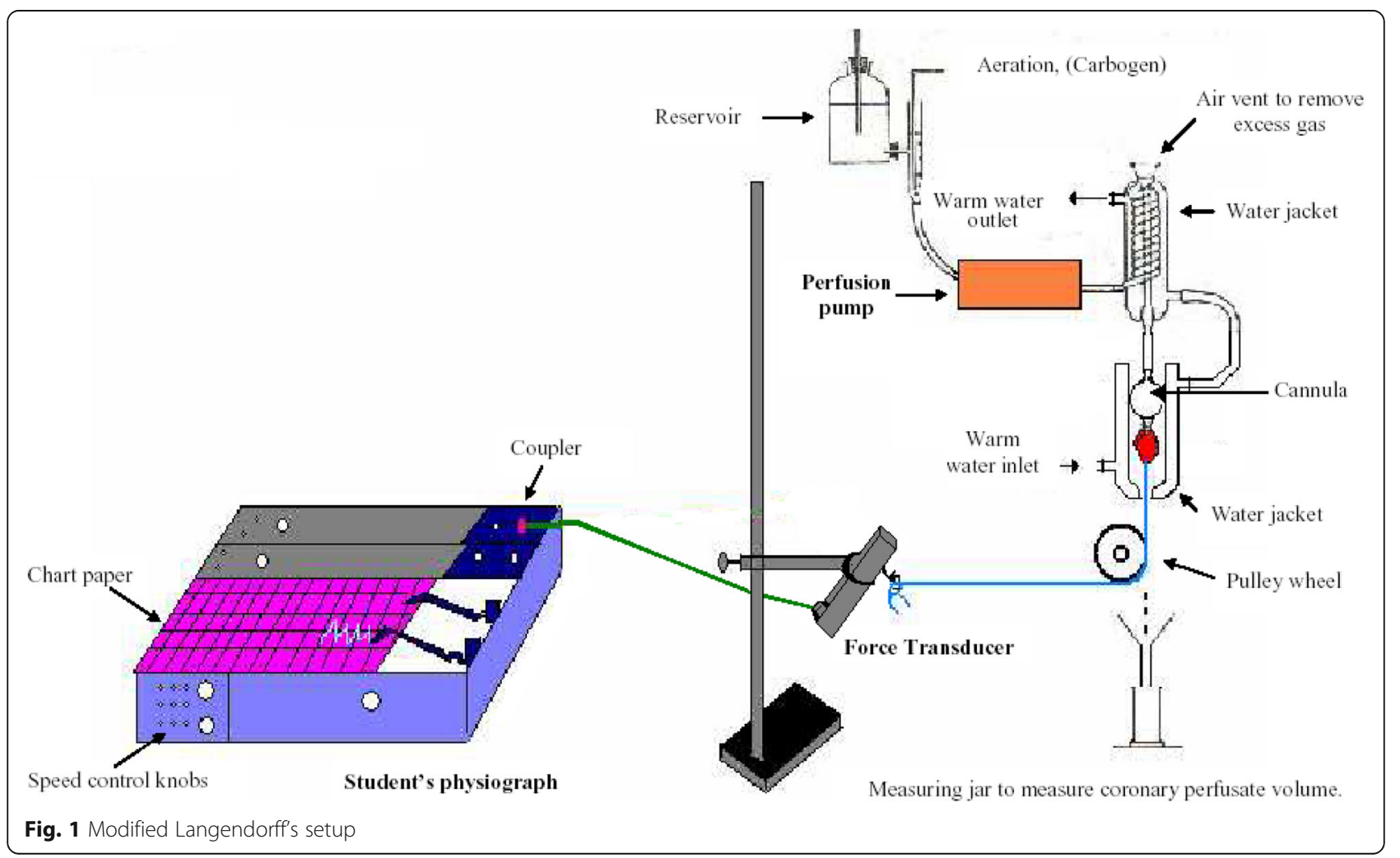


by retro-orbital puncture. Serum was separated by centrifugation for the estimation of biomarkers and evaluation of lipid profile. ECG recordings were made for each animal using lead II. Thereafter, the animals were euthanized through $\mathrm{CO}_{2}$ asphyxiation; four hearts were used for the preparation of homogenate to estimate antioxidants and the remaining four hearts were embedded in formalin (10\%) for histological examination.

Parameters evaluated are as follows: lactate dehydrogenase (LDH), creatinine kinase-MB (CK-MB), creatinine kinase-NAC (CK-NAC), alanine aminotransferase (ALT), aspartate aminotransferase (AST), total cholesterol (TC), and total triglycerides (TG) from serum and superoxide dismutase (SOD), and catalase from tissue homogenate.

\section{Ischemia-reperfusion injury through modified Langendorff setup}

After the end of 7 days of acclimatization period, the animals were randomized into six groups $(n=8)$ as follows:

- Group I (normal control): served as normal control, received physiological saline for 7 days, and were subjected to IRI at the end of the treatment.

- Group II (DTZ): received DTZ (17.5 mg/kg, p.o.) [23] for 7 days and were subjected to IRI at the end of the treatment.

- Group III (STV 100): received a low dose of STV (100 mg/kg, p.o.) for 7 days and were subjected to IRI at the end of the treatment.

- Group IV (STV 200): received a high dose of STV (200 mg/kg, p.o.) for 7 days and were subjected to IRI at the end of the treatment.

- Group V (STV $100+$ DTZ): received a low dose of STV (100 mg $/ \mathrm{kg}$, p.o.) along with DTZ (17.5 mg/kg, p.o.) for 7 days and were subjected to IRI at the end of the treatment.

- Group VI (STV $200+$ DTZ): received a high dose of STV (200 mg/kg, p.o.) along with DTZ (17.5 mg/kg, p.o.) for 7 days and were subjected to IRI at the end of the treatment.

Animals were anesthetized with ketamine $(70 \mathrm{mg} / \mathrm{kg}$, i.p.) and xylazine $(10 \mathrm{mg} / \mathrm{kg}$, i.p.) $2 \mathrm{~h}$ after the last dose of the drug. The heart was quickly removed and mounted on a modified Langendorff apparatus through the aorta (Fig. 1). Animals were heparinized with heparin (100 IU) 30 min before anesthesia. Retrograde perfusion was started with modified Krebs-Henseleit $(\mathrm{KH})$ buffer solution ( $\mathrm{pH}$ 7.4) bubbled with carbogen $\left(95 \% \mathrm{O}_{2}+5 \%\right.$ $\mathrm{CO}_{2}$ ) at a flow rate of $5.5 \mathrm{ml} / \mathrm{min}$ using a regulated perfusion pump. The composition of the modified $\mathrm{KH}$ solution is described in Table 1.
Table 1 Composition of modified KH solution

\begin{tabular}{lll}
\hline Sr. no. & Contents & Quantity $(\mathrm{g} / \mathrm{l})$ \\
\hline 1 & Sodium chloride $(\mathrm{NaCl})$ & 6.9 \\
2 & Magnesium sulphate. $7 \mathrm{H}_{2} \mathrm{O}\left(\mathrm{MgSO}_{4} .7 \mathrm{H}_{2} \mathrm{O}\right)$ & 0.133 \\
3 & Potassium chloride $(\mathrm{KCl})$ & 0.35 \\
4 & Sodium hydrogen carbonate $\left(\mathrm{NaHCO}_{3}\right)$ & 2.1 \\
5 & Sodium hydrogen phosphate $\left(\mathrm{NaHPO}_{4}\right)$ & 0.125 \\
6 & Calcium chloride $\left(\mathrm{CaCl}_{2}\right)$ & 0.28 \\
7 & Glucose & $1-2$ \\
\hline
\end{tabular}

The modified $\mathrm{KH}$ solution was filtered through What$\operatorname{man}^{\circ}$ qualitative filter paper, grade 1 , before use to avoid micro particles that obstruct the coronary arteries. The $\mathrm{pH}$ was adjusted to 7.4 to prevent $\mathrm{KH}$ buffer acidosis occurring due to gassing.

Equilibration period of $10 \mathrm{~min}$ and perfusion period of 15 min was imparted during regular recordings. A student physiograph (INCO, Mumbai, India) was used to measure the contractile force using a force-displacement transducer. Following the initial pre-ischemic perfusion, the heart was subjected to $15 \mathrm{~min}$ of global no-flow ischemia by blocking the flow of $\mathrm{KH}$ solution and carbogen supply followed by $15 \mathrm{~min}$ of reperfusion. The heart rate and developed tension were measured during preischemic and post-ischemic period and recovery (\%) was calculated. Perfusate was collected at post-ischemic period and was used for the determination of diagnostic marker enzymes. The heart was removed and weighed and subjected for either heart tissue homogenate (HTH) preparation or histopathological investigation. Responses were recorded using a force transducer connected to a pre-calibrated physiograph with a resting tension of $2 \mathrm{~g}$ where the developed tension was equivalent to $2 \mathrm{~g}$ on

Table 2 Effect of STV, DTZ, and their combinations on serum enzyme biomarkers in isoproterenol-induced myocardial infarction

\begin{tabular}{|c|c|c|}
\hline \multirow[t]{2}{*}{ Treatment } & \multicolumn{2}{|c|}{ Blood serum level (U/L) } \\
\hline & AST & ALT \\
\hline Normal control & $113.66 \pm 2.57$ & $40.79 \pm 3.15$ \\
\hline ISO control & $480.73 \pm 11.29^{* * *}$ & $190.43 \pm 4.74^{* * *}$ \\
\hline DTZ & 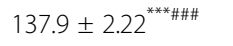 & $107.27 \pm 2.90^{* * \# \# \#}$ \\
\hline STV 100 & $157.06 \pm 2.25^{* * * \# \# \#}$ & $125.33 \pm 2.02^{* * \# \# \#}$ \\
\hline STV 200 & $135.60 \pm 2.02^{* * * \# \# \#}$ & $102.47 \pm 3.80^{* * * \# \# \#}$ \\
\hline STV 100+ DTZ & $130.13 \pm 2.04^{* * \# \# \#}$ & 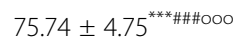 \\
\hline STV $200+$ DTZ & $106.73 \pm 2.52^{\# \# \# \circ \circ \circ}$ & 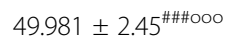 \\
\hline
\end{tabular}

Results are expressed as mean \pm SEM, $n=8$

${ }^{* *} P<0.01$

${ }^{* * *} P<0.001$ when compared to normal

\#\#\# $P<0.001$ when compared to ISO control

${ }^{\circ 0} p<0.01$

${ }^{\circ 00} P<0.001$ when compared to DTZ 
Table 3 Effect of STV, DTZ, and their combinations on electrocardiographic parameters in isoproterenol-induced myocardial infarction

\begin{tabular}{|c|c|c|c|c|c|}
\hline Treatment & Heart rate & $\mathrm{RR}(\mathrm{ms})$ & QRS (ms) & QT (ms) & PR (ms) \\
\hline Normal control & $191.64 \pm 7.39$ & $187.96 \pm 4.43$ & $137.26 \pm 3.31$ & $196.51 \pm 3.34$ & $62.85 \pm 4.59$ \\
\hline ISO control & $298.52 \pm 10.83^{* * *}$ & $288.74 \pm 4.26^{* * *}$ & $183.52 \pm 2.98^{* * *}$ & $263.39 \pm 3.65^{* * *}$ & $113.70 \pm 3.89^{* * *}$ \\
\hline DTZ & $238.48 \pm 7.15^{* * * \# \# \#}$ & $254.8 \pm 2.64^{* * * \# \# \#}$ & $162.20 \pm 1.56^{* * * \# \#}$ & $220.86 \pm 2.38^{* * * \# \# \#}$ & $85.23 \pm 2.11^{* * \# \# \#}$ \\
\hline STV 100 & $268.59 \pm 14.73^{* * * \# \# \#}$ & $261.83 \pm 1.48^{* * * \# \# \#}$ & $162.91 \pm 2.97^{* * * \# \#}$ & $234.06 \pm 1.79^{* * * \# \# \#}$ & $94.95 \pm 1.11^{* * * \# \#}$ \\
\hline STV 200 & $242.10 \pm 9.47^{* * * \# \# \#}$ & $253.45 \pm 3.08^{* * * \# \# \#}$ & $164.46 \pm 2.92^{* * * \# \#}$ & $218.12 \pm 2.00^{* * \# \# \#}$ & $84.73 \pm 1.15^{* * \# \# \#}$ \\
\hline STV 100+ DTZ & $227.29 \pm 4.38^{* * * \# \# \#}$ & 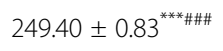 & 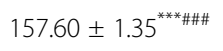 & $220.24 \pm 4.06^{* * \# \# \#}$ & $85.58 \pm 2.78^{* * \# \# \#}$ \\
\hline STV 200 + DTZ & $211.53 \pm 5.96^{\# \# \# \circ \circ}$ & $237.56 \pm 1.78^{* \# \# \# 0}$ & $146.47 \pm 3.38^{\# \# \# \circ}$ & $199.73 \pm 3.34^{\# \# \# \circ \circ ~}$ & 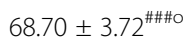 \\
\hline
\end{tabular}

Results are expressed as mean \pm SEM, $n=8$

${ }^{*} P<0.05$

${ }^{* *} P<0.01$

${ }^{* * *} P<0.001$ when compared to normal

$\# \#<0.01$

\#\#\# $P<0.001$ when compared to ISO control

${ }^{\circ} P<0.05$

${ }^{\circ 0} P<0.01$ when compared to DTZ

graph paper. The paper speed was adjusted to a minimum $0.05 \mathrm{~mm} / \mathrm{sec}$ and the sensitivity of transducer was adjusted to maximum, i.e., $0.1 \mathrm{mV}$.

Parameters evaluated are as follows: lactate dehydrogenase (LDH), creatinine kinase-MB (CK-MB), creatinine kinase-NAC (CK-NAC), alanine aminotransferase (ALT), aspartate aminotransferase (AST), total cholesterol (TC), and total triglycerides (TG) from perfusate and superoxide dismutase (SOD) and catalase from tissue homogenate.

\section{Biochemical analysis}

At the end of the experimental period, animals were anesthetized with ketamine $(70 \mathrm{mg} / \mathrm{kg}$, i.p.) and xylazine $(10 \mathrm{mg} / \mathrm{kg}$, i.p.); and blood was withdrawn by retroorbital puncture using micro-capillaries. Serum then separated from blood and perfusate collected after reperfusion was used in estimation of LDH, CK-MB, CKNAC, ALT, AST. Four hearts from each group were homogenized with $0.025 \mathrm{M}$ Tris-HCL buffer ( $\mathrm{pH}$ 7.4) for the estimation of SOD and catalase enzymes. Determination of SOD activity was done on the basis of capacity of reduction of nitro blue tetrazolium by the enzyme and catalase was determined by the method described by Aebi [24].

\section{Electrocardiographic studies}

At the end of the treatment, the animals were anesthetized with the combination of ketamine $(70 \mathrm{mg} / \mathrm{kg}$, i.p.) and xylazine $(10 \mathrm{mg} / \mathrm{kg}$, i.p.). A digital physiograph (Model number DI-2, INCO, Ambala, India) was used for recording. Leads were attached to all four limbs in

\section{Changes in Biomarker Levels}

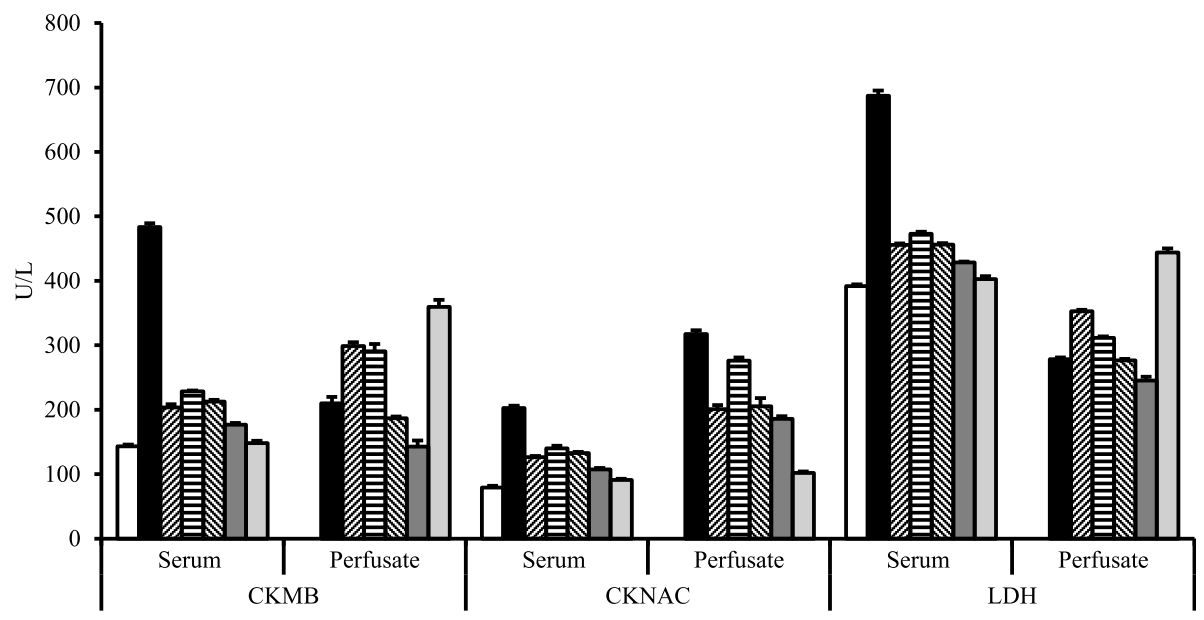

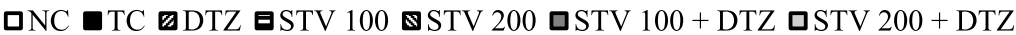

Fig. 2 Effects of STV, DTZ, and their combinations of levels of CKMB, CKNAC, and LDH levels in serum and perfusate 


\section{Changes in TC and TG Levels}

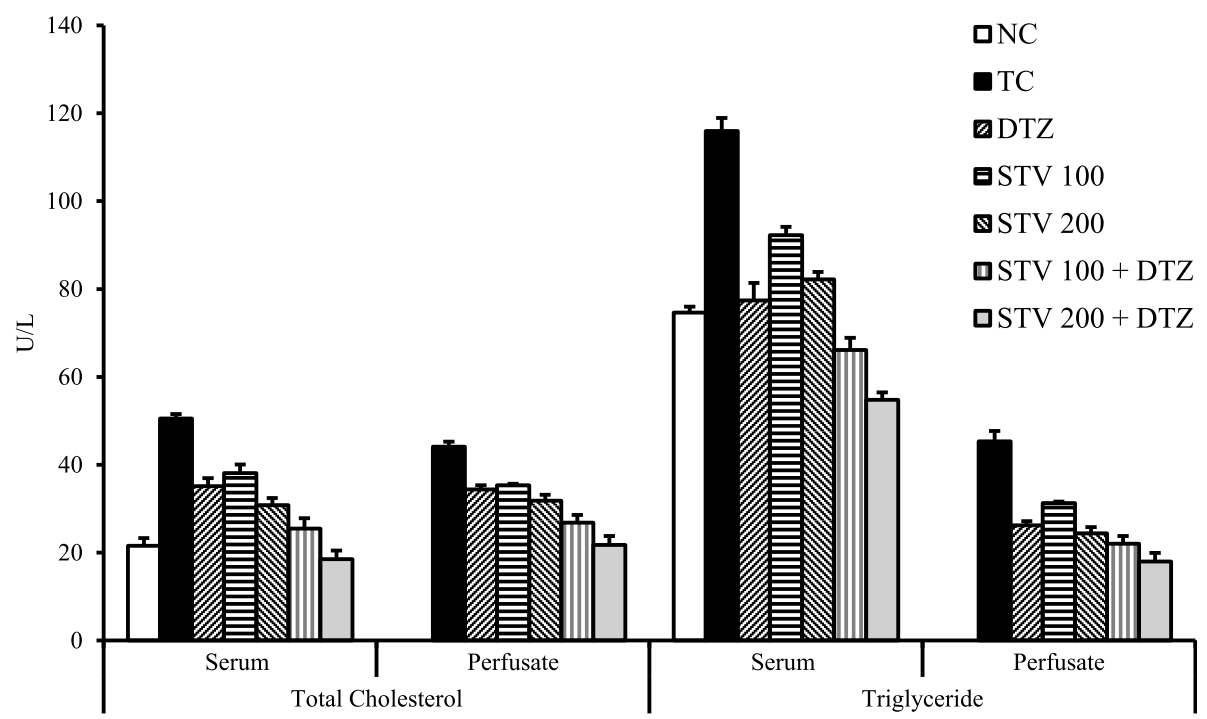

Fig. 3 Effect of STV, DTZ, and their combination on total cholesterol and triglycerides levels

the dermal layer. Parameters evaluated were heart rate, QRS, QT, PR, and RR intervals.

\section{Lipid profile assay}

Cholesterol and triglycerides levels were measured from serum and perfusate by commercial kits with the help of a semi auto-analyzer (Prietest TOUCH, Robonik (India) Pvt. Ltd.).

\section{Histopathological analysis}

Hearts were removed immediately from the sacrificed animals, washed with saline, and were fixed in $10 \%$ formalin before being processed for histopathological analysis. Tissues were stained with hematoxylin and eosin. Myocardial damage was classified as either no changes, mild, moderate, or marked [25].

\section{Statistical analysis}

InStat data analysis program was used for statistical analysis (GraphPad Software, USA). Data were analyzed by one-way analysis of variance (ANOVA) and presented as means \pm standard error mean (SEM). Individual differences were determined by Tukey-Karmer multiple

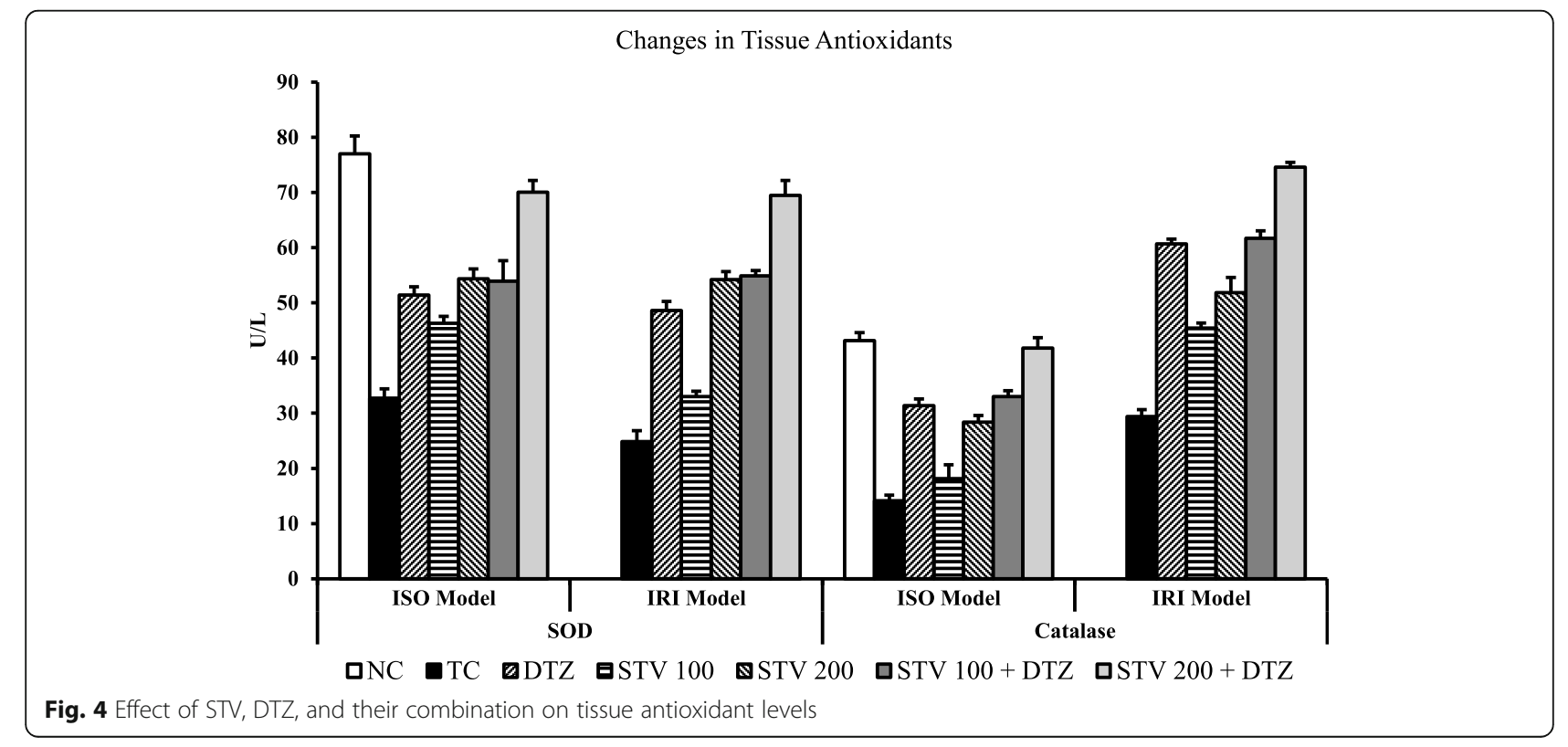



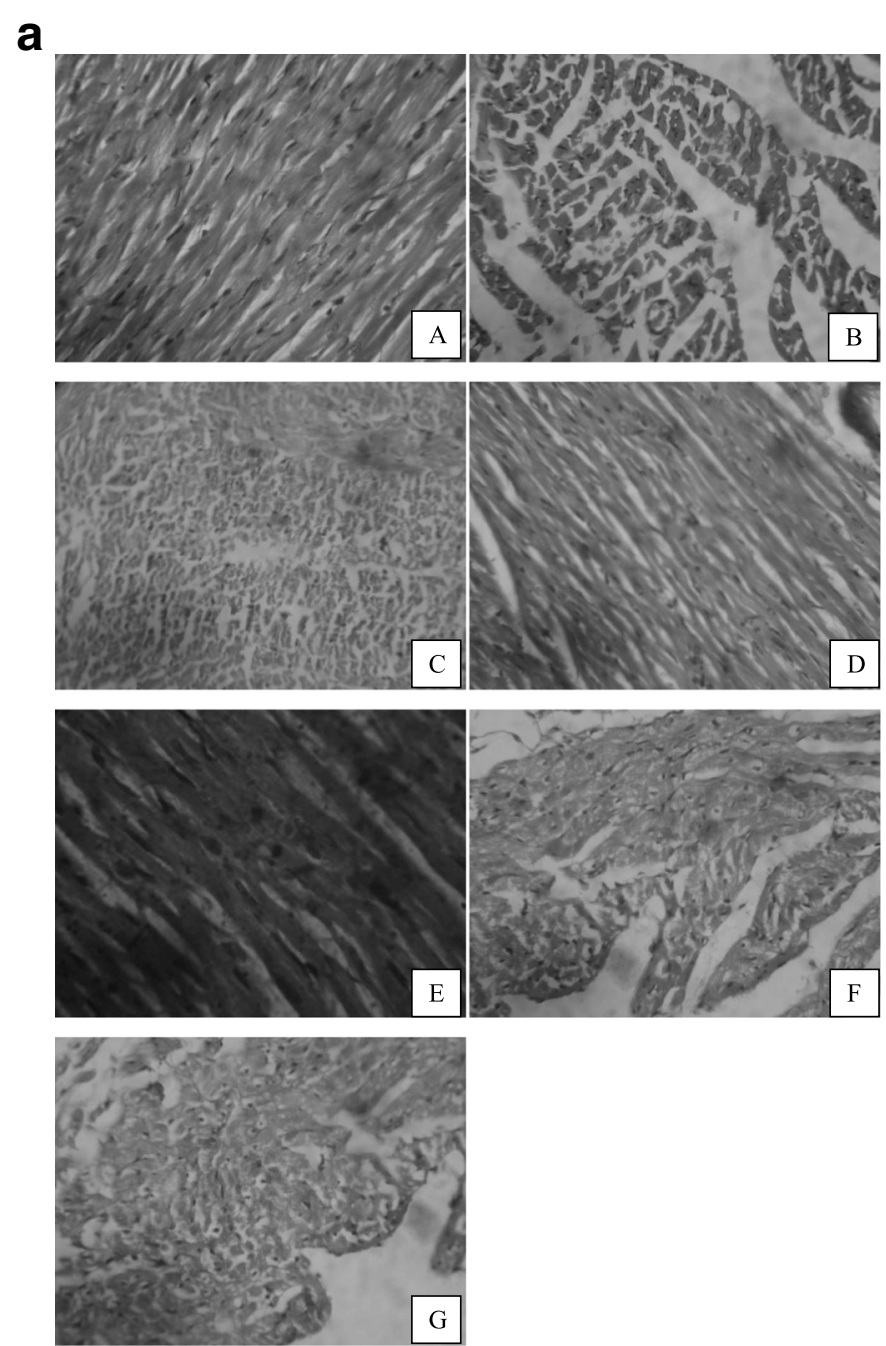

\section{b}
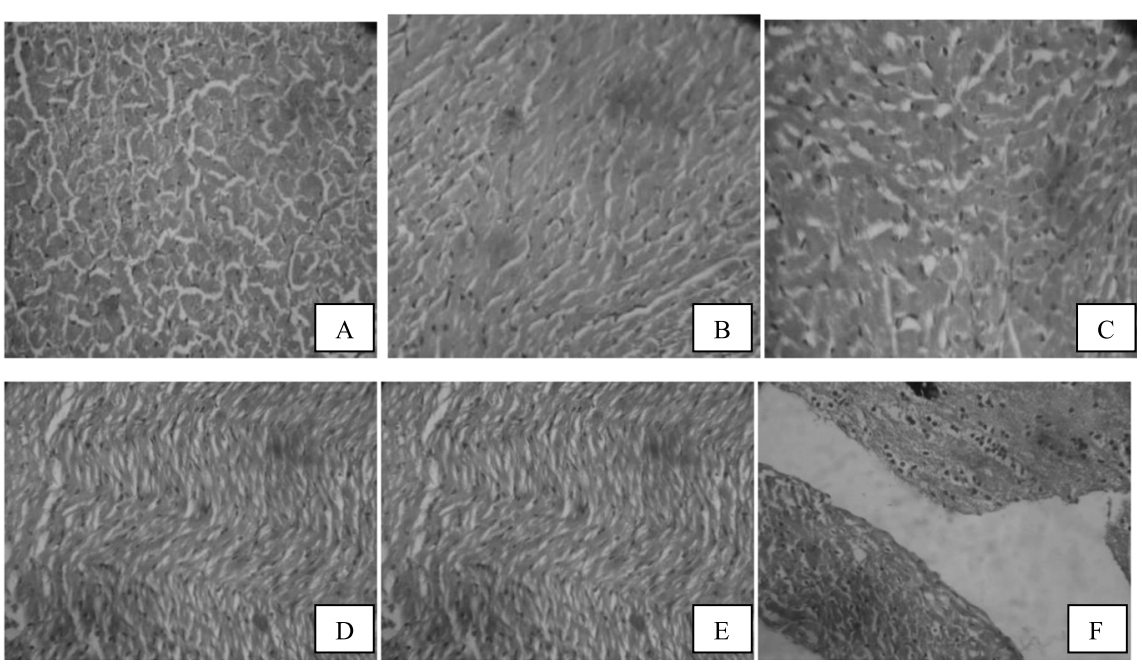

Fig. 5 a Photomicrographs $(\times 400)$ of hematoxylin and eosin stained heart tissues of different treatment groups: (a) normal control (b) ISO control (c) DTZ (d) STV 100 (e) STV 200 (f) STV 100 + DTZ (g) STV 100 + DTZ. b Photomicrographs ( $\times$ 400) of hematoxylin and eosin stained heart tissues of different treatment groups: (a) IRI control (b) DTZ (c) STV 100 (d) STV 200 (e) STV 100 + DTZ (f) STV 100 + DTZ 
comparison tests. A value of less than 0.05 was considered statistically significant.

\section{Results}

Acute toxicity

The acute oral toxicity study was performed according to the OPPTS guidelines (Office of Prevention, Pesticide and Toxic Substance) following the limit test procedure. Test dose of $2 \mathrm{~g} / \mathrm{kg}$ and $5 \mathrm{~g} / \mathrm{kg}$ were given orally to mice. No mortality was observed in the treated animals. Both doses were found to be safe. Hence, 1/50th and 1/25th of the maximum safe dose corresponding to $100 \mathrm{mg} / \mathrm{kg}$ and $200 \mathrm{mg} / \mathrm{kg}$ orally were selected as low and high doses respectively.

\section{Isoproterenol-induced myocardial infarction}

Serum levels of biomarkers CK-MB, CK-NAC, LDH, AST, ALT, TC, and TG significantly increased in the ISO control group when compared to normal control confirming the toxicity of ISO. Standard DTZ showed a significant decrease in the serum levels of the biomarkers as predicted when compared to the ISO control group. Stevioside in both low and high doses significantly prevented myocardial injury by ISO. Stevioside in combination with DTZ showed a dose-dependent protective response against ISO-induced infarction when compared with the DTZ group. Electrocardiographic parameters $H R, R R, Q R S, Q T$, and PR were significantly altered in the ISO control group. DTZ pre-treatment normalized these parameters. Stevioside alone and in combination with DTZ showed significant improvement in electrocardiographic parameters, indicating its cardioprotective property alone and in combination. Antioxidant enzyme levels were significantly reduced in the toxic control group treated with ISO. DTZ, stevioside, and combination groups of DTZ with STV showed membrane protective action by limiting the amounts of antioxidants leaked into the systemic circulation. SOD and catalase levels were normalized in these treatment groups. Histopathologically, STV and DTZ treatment groups showed improved myocardial cellular integrity when compared to the ISO control group. Combination groups, STV + DTZ, at both doses, displayed clear protective effect of each of the drugs as restored myocardium cells were observed in both the dose groups (Tables 2, 3; Figs. 2, 3, 4 and 5).

\section{Ischemia reperfusion injury through modified Langendorff setup}

Oral pre-treatment of DTZ and STV in alone and in combination showed a significant increase in perfusate levels of CK-MB, CK-NAC, LDH, AST, ALT, TC, and TG when compared to IRI control group. STV + DTZ combination groups also displayed significant changes in
Table 4 Effect on STV, DTZ, and their combinations on perfusate biomarker levels in IRI

\begin{tabular}{lll}
\hline Treatment & \multicolumn{2}{l}{ Perfusate level (U/L) } \\
\cline { 2 - 3 } & ALT & AST \\
\hline IRI control & $17.08 \pm 1.08$ & $37.37 \pm 1.23$ \\
DTZ & $22.46 \pm 0.88^{* *}$ & $51.39 \pm 3.31^{* * *}$ \\
STV 100 & $18.25 \pm 0.62^{* * *}$ & $42.08 \pm 3.13^{* * *}$ \\
STV 200 & $16.97 \pm 0.99^{* * *}$ & $30.12 \pm 1.22^{* * *}$ \\
STV 100 + DTZ & $9.37 \pm 1.30^{* * * 0}$ & $19.10 \pm 1.15^{* * * 000}$ \\
STV 200 + DTZ & $32.19 \pm 2.97$ & $72.44 \pm 3.27$ \\
\hline
\end{tabular}

Results are expressed as mean \pm SEM, $n=8$

${ }^{*} P<0.05$

${ }^{* *} P<0.01$

${ }^{* * *} P<0.001$ when compared to IRI control

${ }^{\circ} P<0.05$

${ }^{\circ 00} P<0.001$ when compared to DTZ

perfusate levels when compared to the DTZ control group. IRI control group displayed low levels of antioxidant enzymes SOD and catalase in heart tissue homogenate. DTZ and STV groups showed a dose dependent significant increase in the levels of these antioxidant enzymes, showing protective action on the myocardial integrity. On comparing percentage recovery of tension developed in the DTZ group with that in the IRI control group, a significant recovery trend was observed in the tension of DTZ group animals. STV alone and in combination with DTZ showed higher \% recovery than the DTZ control group. IRI control group showed decreased heart rate. Pre-treatment with DTZ and STV showed significant recovery and normalization of heart rate. Histopathologically, IRI control hearts showed myocardial cell separation, cytoplasmic eosinophils and aggregation of inflammatory cell groups. DTZ pre-

Table 5 Effect of STV, DTZ, and their combinations on \% recovery in terms of developed tension and heart rate against $|R|$ damage in IRI

\begin{tabular}{lll}
\hline Treatment & \% recovery \\
\cline { 2 - 3 } & Developed tension & Heart rate \\
\hline IRI control & $29.11 \pm 1.85$ & $31.68 \pm 1.32$ \\
DTZ & $43.27 \pm 2.03^{* *}$ & $61.44 \pm 1.85^{* * *}$ \\
STV 100 & $44.69 \pm 2.07^{* * *}$ & $55.51 \pm 2.22^{* * *}$ \\
STV 200 & $51.60 \pm 1.29^{* * *}$ & $56.65 \pm 4.64^{* * *}$ \\
STV 100+ DTZ & $57.07 \pm 1.58^{* * * \circ 0}$ & $72.67 \pm 5.74^{* * * \circ O}$ \\
STV 200 + DTZ & $93.87 \pm 1.92^{* * * 000}$ & $88.9 \pm 8.36^{* * * \circ o \circ}$ \\
\hline
\end{tabular}

Results are expressed as mean \pm SEM, $n=8$

${ }^{* *} P<0.01$

${ }^{* * *} P<0.001$ when compared to IRI control

${ }^{\circ 0} P<0.01$

${ }^{\circ 0 \circ} P<0.001$ when compared to DTZ 


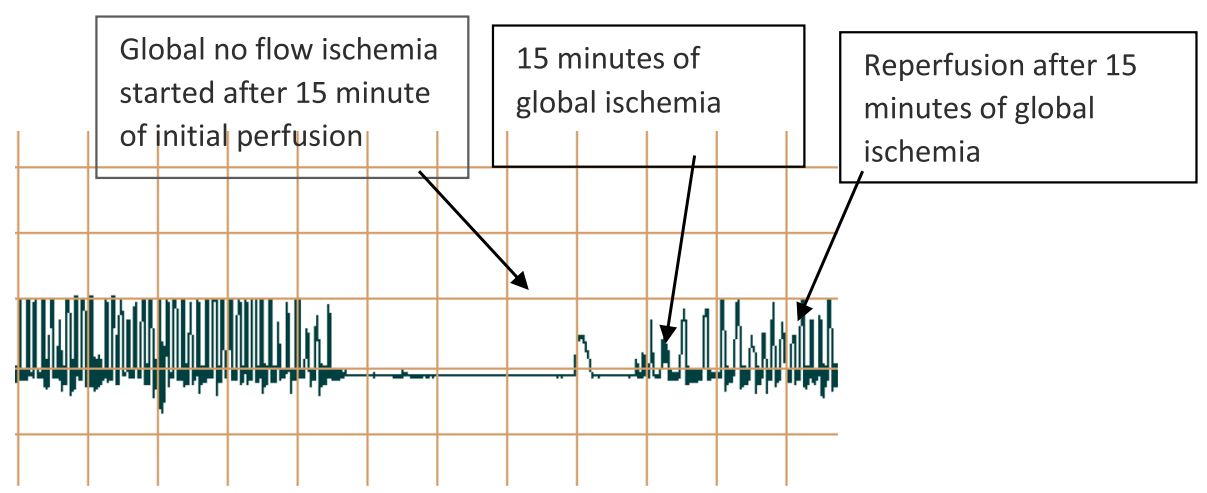

Fig. 6 Tracing on Polygraph of IRI control

treated hearts showed normal vasculature. STV-100 and STV-200 treated group showed occasional fiber loss, coagulated necrosis and inflammatory cells. Combination groups DTZ + STV had mild to minimal inflammatory damage and few inflammatory cells (Tables 4,5 ; Figs. 2, $3,4,5,6,7,8,9,10$ and 11).

\section{Discussion}

Stevioside and rebaudioside A are steviol glycosides found in the leaves of Stevia rebaudiana. Apart from the traditional use as a sweetener, stevioside possesses a range of different therapeutic properties [9]. The current research was designed to evaluate the cardioprotective activity of STV and its possible interaction with conventional calcium channel blocker DTZ against isoproterenol-induced myocardial infarction and ischemia reperfusion-induced myocardial damage in Wistar rats. The findings of the investigations witnessed the beneficial role of STV alone and when treated concurrently with DTZ in conditions of anticipated cardiac injury.

Isoproterenol, a synthetic catecholamine and $\beta$ adrenoceptor stimulant, causes myocardial damage at higher concentrations [26]. ISO generates free radical and stimulates lipid peroxidation leading to the irreversible damage of the myocardial cell membrane. Treatment with ISO causes a rise in uptake of calcium and consumption of energy which ultimately leads to cell death [26]. In the present study, ISOinduced MI was confirmed by elevated serum levels of biomarker enzymes-CK-NAC and isoenzyme CK$\mathrm{MB}$ (cardiac muscle fraction of CK). ISO-induced cellular changes include increased permeability of the cell membrane, cellular damage with loss of functional integrity, and eventually myocardial necrosis. This was supported by an increase in serum levels of LDH, AST, and ALT enzymes. In this study, we also observed increased levels of total cholesterol and triglycerides that positively correlate with an increase in lipid biosynthesis, eventually leading to coronary heart disease [27]. It has been suggested that the oxidative products of catecholamines produce changes in the myocardium by stimulating lipid peroxidation and cause irreversible damage to the myocardial membrane $[28,29]$. This damage negatively affects membrane permeability, which causes

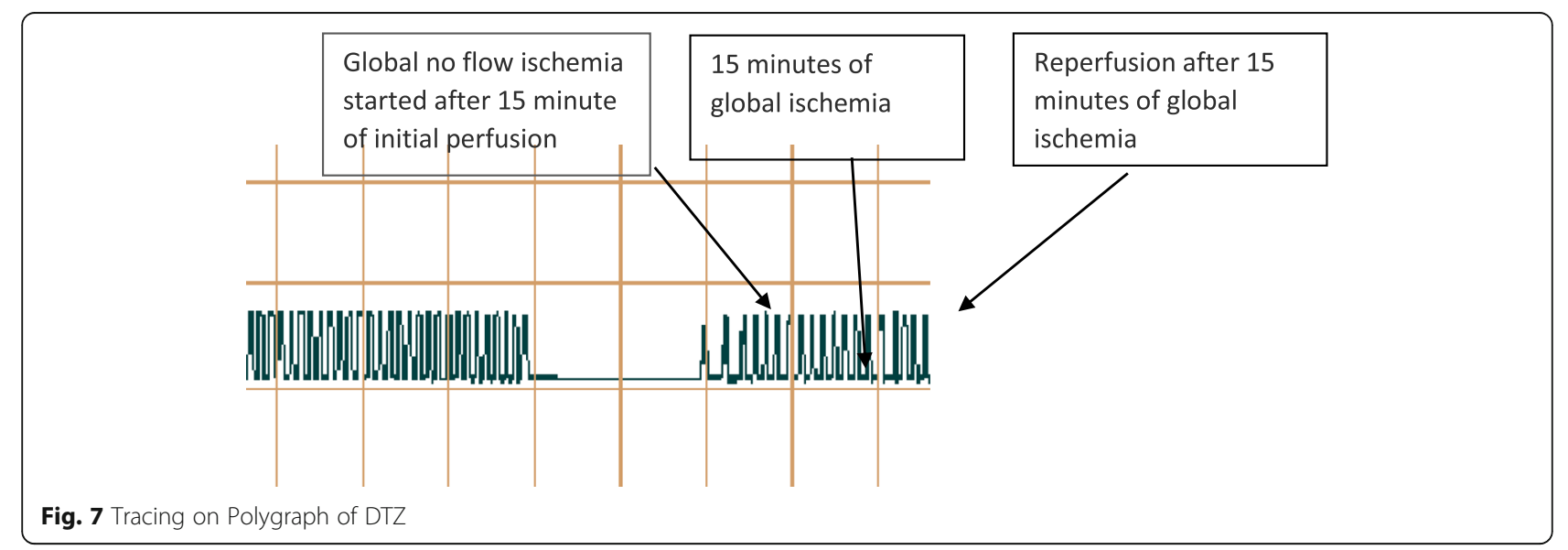




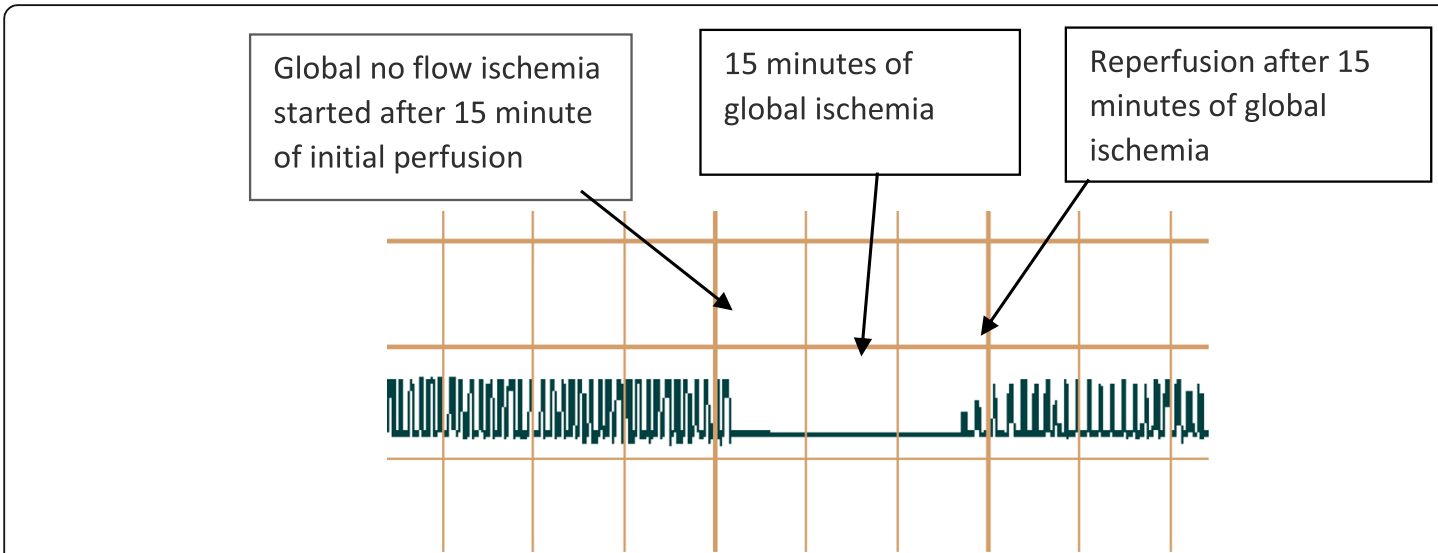

Fig. 8 Tracing on Polygraph of STV-100

loss of membrane function and integrity. Hence, leakage of endogenous biological markers and free radical formation is attributed for myocardial distress in post-ISO administration [29]. Pretreatment with STV markedly normalized serum biomarker levels and improved lipid profile. It suggests that STV could maintain cellular integrity and thereby restrict the leakage of biomarkers. The lipid-lowering action may be attributed to the phytoconstituent's ability to stimulate excretion of bile acid and stimulate the action of the enzyme, 3-hydroxy-3-methylglutaryl CoA reductase (HMG-CoA), resulting in increased hepatic cholesterogenesis and decrease in serum cholesterol levels. Activation of peroxisome proliferatorsactivated receptors (PPARs) and increased expression of the lipoprotein lipase (LPL) by interaction of STV with PPARs resulted in decreased serum triglycerides levels [30]. In this study, decreased activities of SOD and catalase were observed in ISO control animals. It is a result of the formation of superoxide anions and hydrogen peroxide caused by lipid peroxidation of myocardial tissues [29]. STV displayed protective activity in a dose dependent manner by scavenging oxidative free radicals [16] and diminishing the permeability of these endogenous biomarkers to surrounding cardiac regions. DTZ blocks calcium channels in myocardium leading to a decrease in preload and afterload by blocking influx of calcium [31]. As a consequence, a combination of DTZ and STV witnessed synergistic cardioprotection to the myocardium.

Electrocardiographic parameters are the primary diagnostic tools in MI. Excessive activation of the sympathetic system by ISO accompanied by vagal hypoactivity produces severe myocardial damage. Resultant myocardial infarction can be interpreted from the disturbance or changes in the ECG pattern of the respective subject due to ISO. In this study, during the first few hours, the amplitude of $\mathrm{T}$ waves increased abnormally (hyperacute with loss of their normal concavity) accompanied by vagal hypoactivity and the ST segments began to rise. The sympathetic hyperactivity has a direct impact on ECG by extension of the QT interval. The prolongation QT interval at times of myocardial stress is an indication of arrhythmias and sudden cardiac collapse [32-34].

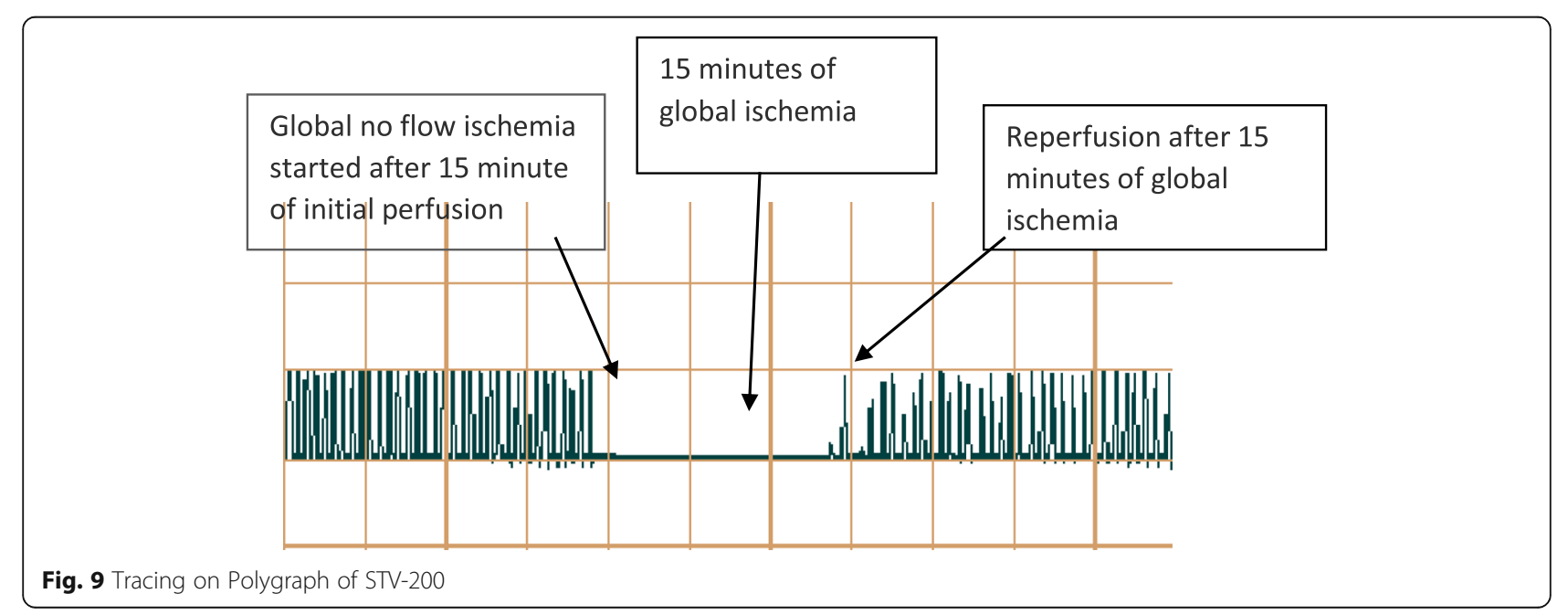




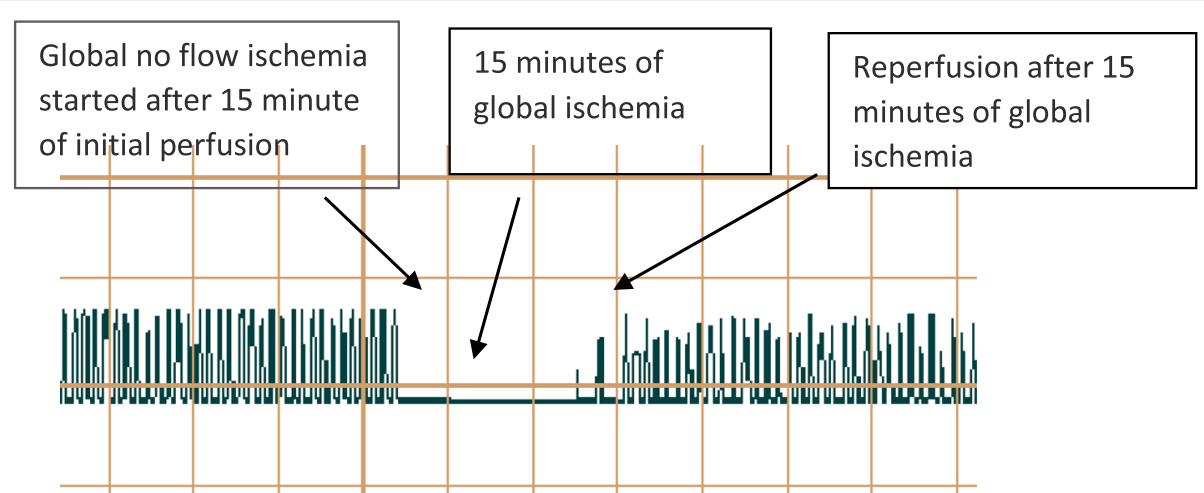

Fig. 10 Tracing on Polygraph of STV-100 + DTZ

Oral pre-treatment of STV-100 and STV-200 alone and with DTZ was potent enough to avoid prolongation of QT interval representing the absence of arrhythmias. Similarly, abnormally elevated QRS duration, PR and RR intervals are also predictors for myocardial damage [35]. Prophylactic treatment of animals with STV- $100 / 200 \mathrm{mg} / \mathrm{kg}$, DTZ, and their combinations showed maximum normalization in electrocardiographic determination. Among the above treatments, the best result was observed by a high dose of STV when given with DTZ in conjugation before induction of myocardial damage by ISO.

In the ischemic reperfusion injury (IRI) model, induction of myocardial injury was done by restricting the flow of carbogenated $\mathrm{KH}$ that produces ischemia followed by reperfusion, which further increases the extent of damage. Sudden occlusion of physiological salt solution results in immediate biochemical alterations. The increase in intracellular $\mathrm{Na}^{+}$serves to drive $\mathrm{Ca}^{+2}$ intracellularly via $\mathrm{Na}^{+} / \mathrm{Ca}^{+2}$ exchange that results in irreversible damage to the myocardium at the end of $15 \mathrm{~min}$ global ischemia [36]. In the present study, it was observed that the oral pre-treatment of STV-100, STV-200, alone, and along with DTZ decreases the biomarker activities in the perfusate. The combination of STV-200 and DTZ was proposed to be the best effective combination to their individual treatments based on the obtained data in the given experimental conditions.

Histopathological examination in IRI control animals showed myocardial edema, fiber separation, and striation loss as indications of myocardial injury. The myocardial edema and separation of fibers were ameliorated with treatment of STV-200 alone. The protective effect of STV-200 was further augmented when administered concurrently with DTZ.

The mechanism of cardioprotection by STV can be attributed to its free radical scavenging potential and ability to maintain cellular integrity. Lipid-lowering action via HMG-CoA and LPL stimulation and calcium channel blocking action provides support to the protection against secondary effects of cardiotoxicity. Synergistic effect was observed when stevioside was co-administered with diltiazem during myocardial damage indicating an interaction between the two drugs.

\section{Conclusion}

It can be concluded from the present study that stevioside exerts cardioprotective activity alone and in combination with the standard calcium channel blocker,

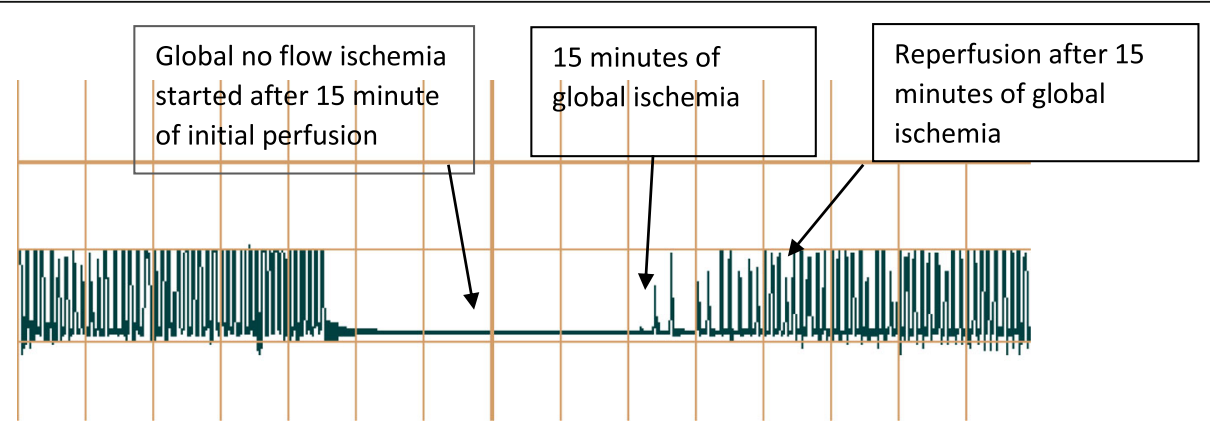

Fig. 11 Tracing on Polygraph of STV-200 + DTZ 
diltiazem. Findings from this study can be used for further investigation into the mechanism of interaction between the two drugs, metabolic profiling, and the probability of bioenhancement of diltiazem by stevioside. Fixed-dose combinations of the two can be tested to decrease the adverse effects of diltiazem.

\section{Abbreviations}

ALT: Alanine aminotransferase; ANOVA: One-way analysis of variance; AST: Aspartate aminotransferase; CK-MB: Creatinine kinase-MB; CKNAC: Creatinine kinase-NAC; CPCSEA: Committee for the Purpose of Control and Supervision of Experiments on Animals; DTZ: Diltiazem; ECG: Electrocardiogram; HCL: Hydrochloride; HMG-CoA: 3-hydroxy-3methylglutaryl CoA reductase; $\mathrm{HTH}$ : Heart tissue homogenate; i.p.: Intraperitoneal; IAEC: Institutional Animal Ethics Committee; IL1ß: Interleukin 1 beta; IRI: Ischemia reperfusion injury; ISO: Isoproterenol; IU: International Unit; KH: Modified Krebs Henseleit buffer solution; LDH: Lactate dehydrogenase; LPL: Lipoprotein lipase;

LPS: Lipopolysaccharides; MI: Myocardial infarction; NF-KB: Nuclear factorkappa B pathway; OPPTS: Office of Prevention of Pesticide and Toxic Substance; p.o.: Per os, oral administration; PPARs: Peroxisome proliferatorsactivated receptors; s.c.: Subcutaneous; SEM: Standard error mean; SOD: Superoxide dismutase; STV: Stevioside; TC: Total cholesterol; TG: Triglycerides; TNF-a: Tumor necrosis factor alpha

\section{Acknowledgements}

The authors are grateful to the Shree Devi Education trust for providing the facilities for conduct of this research and to the staff at Shree Devi College of Pharmacy, Mangalore.

\section{Authors' contributions}

$\mathrm{JA}, \mathrm{MC}$, and $\mathrm{JV}$ conceived the idea and designed the experiment. $\mathrm{LB}$ and $\mathrm{JA}$ performed the experimental part and statistical evaluation. LB and JA wrote the manuscript. $L B, J A$, and $M C$ interpreted the data. $L B$ as the corresponding author executed the submission and approved the manuscript from all co-authors.

\section{Funding}

This research did not receive any specific grant from funding agencies in the public, commercial, or not-for-profit sectors.

\section{Availability of data and materials}

The data used to analyze the findings of this study are available from the corresponding author upon request.

\section{Ethics approval and consent to participate}

The animal experiments complied with the ARRIVE guidelines, Guide for the Care and Use of Laboratory Animals, and guidelines provided by the Committee for the Purpose of Control and Supervision of Experiments on Animals (CPCSEA), the Ministry of Social Justices and Empowerment, Government of India. The approval for animal experimentation was obtained from the Institutional Animal Ethics Committee (certificate number: SDCP/ IAEC-14/2011-12).

\section{Consent for publication}

Not applicable

\section{Competing interests}

The authors declare that they have no competing interests.

Received: 24 March 2020 Accepted: 6 July 2020

Published online: 17 July 2020

\section{References}

1. Kochanek KD, Murphy SL, Xu J, Tejada-Vera B (2016) Deaths: final data for 2014. Natl Vital Stat Rep 65:1-122

2. Centers for Disease Control and Prevention (CDC) (2007) Prevalence of selfreported cardiovascular disease among persons aged \&gt; or $=35$ years with diabetes--United States, 1997-2005. MMWR Morb Mortal Wkly Rep 56:11291132
3. Braunwald E, Bonow RO (2012) Braunwald's heart disease: a textbook of cardiovascular medicine. Elsevier Saunders

4. Singh YN (2005) Potential for interaction of kava and St. John's wort with drugs. J Ethnopharmacol 100:108-113

5. Bhatt L, Maithani S (2017) Protective effects of a polyherbal formulation, freemodex, against acute models of pain, inflammation, arthritis, and immunosuppression. Int J Nutr Pharmacol Neurol Dis https://doi.org/10. 4103/ijnpnd.ijnpnd

6. Rahila K, Bhatt L, Chakraborty M, Kamath J, Rahila K (2013) Hepatoprotective activity of Crotalaria juncea against thioacetamide intoxicated rats. Int Res J Pharm Appl Sci 3:98-101

7. Mukherjee PK (2015) Evidence-based validation of herbal medicine. Elsevier Science

8. Ho JWS, Cheung MWM (2014) Combination of phytochemicals as adjuvants for cancer therapy. Recent Pat Anticancer Drug Discov 9:297-302

9. Chatsudthipong V, Muanprasat C (2009) Stevioside and related compounds: therapeutic benefits beyond sweetness. Pharmacol Ther 121:41-54

10. Liu J-C, Kao P-K, Chan P, Hsu Y-H, Hou C-C, Lien G-S, Hsieh M-H, Chen Y-J, Cheng J-T (2003) Mechanism of the antihypertensive effect of stevioside in anesthetized dogs. Pharmacology 67:14-20

11. Jeppesen PB, Gregersen S, Rolfsen SED, Jepsen M, Colombo M, Agger A Xiao J, Kruhøffer M, Ørntoft T, Hermansen K (2003) Antihyperglycemic and blood pressure-reducing effects of stevioside in the diabetic Goto-Kakizaki rat. Metabolism 52:372-378

12. Hsieh MH, Chan P, Sue YM, Liu JC, Liang TH, Huang TY, Tomlinson B, Chow MSS, Kao PF, Chen YJ (2003) Efficacy and tolerability of oral stevioside in patients with mild essential hypertension: a two-year, randomized, placebocontrolled study. Clin Ther 25:2797-2808

13. Milijaševi B, Vasovi V, Raškovi A, Mikov M, Mikov I, Vukmirovi S, Budakov Z (2014) VOJNOSANITETSKI PREGLED Strana 667 Effect of aqueous solution of stevioside on pharmacological properties of some cardioactive drugs Uticaj vodenog rastvora steviozida na farmakološka svojstva nekih kardioaktivnih lekova. Vojnosanit Pregl 71:667-672

14. Bunprajun T, Yimlamai T, Soodvilai S, Muanprasat C, Chatsudthipong V (2012) Stevioside enhances satellite cell activation by inhibiting of NF-KB signaling pathway in regenerating muscle after cardiotoxin-induced injury. J Agric Food Chem 60:2844-2851

15. Jeppesen PB, Gregersen S, Poulsen CR, Hermansen K (2000) Stevioside acts directly on pancreatic $\beta$ cells to secrete insulin: actions independent of cyclic adenosine monophosphate and adenosine triphosphate-sensitive $\mathrm{K}+$ -channel activity. Metabolism 49:208-214

16. Stoyanova S, Geuns J, Hideg É, Van Den Ende W (2011) The food additives inulin and stevioside counteract oxidative stress. Int J Food Sci Nutr 62:207-214

17. Gómez-Alvis A, Rebolledo A, Milesi V, Raingo J, Sanz N, Tommasi J, Drago A, Rinaldi G, Grassi A (2004) Cardiac and vascular effects of diltiazem, dobutamine and amrinone, drugs used after myocardial revascularization. Braz J Med Biol Res 37:893-900

18. Kraus RL, Hering S, Grabner M, Ostler D, Striessnig J (1998) Molecular mechanism of diltiazem interaction with L-type Ca2+ channels. J Biol Chem 273:27205-27212

19. Mason PK, Malhotra R (2019) 39 - antidysrhythmic electrophysiology and pharmacotherapy. Card Intensive Care. https://doi.org/10.1016/B978-0-32352993-8.00039-4

20. Schroeder JS, Frishman WH, Parker JD, Angiolillo DJ, Woods C, Scirica BM (2012) Pharmacologic options for treatment of ischemic disease. In: Cardiovasc. Ther. A Companion to Braunwald's Hear. Dis. Fourth Ed. Elsevier Inc., pp 83-130

21. Olshansky B, Chung MK, Pogwizd SM, Goldschlager N (2017) Treatment of arrhythmias. In: Arrhythmia Essentials. Elsevier, pp 357-396

22. Patel V, Upaganlawar A, Zalawadia R, Balaraman R (2010) Cardioprotective effect of melatonin against isoproterenol induced myocardial infarction in rats: a biochemical, electrocardiographic and histoarchitectural evaluation. Eur J Pharmacol 644:160-168

23. Yousef WM, Omar AH, Ghanayem NM, Mohamed M, El-Wahed A, Morsy MD (2005) Effect of some calcium channel blockers in experimentally induced diabetic nephropathy in rats. Int J Diabetes Metab 14:39-49

24. Bhatt L, Sebastian B, Joshi V (2017) Mangiferin protects rat myocardial tissue against cyclophosphamide induced cardiotoxicity. J Ayurveda Integr Med 8:62-67

25. Chakraborty M, Kamath J, Bhattacharjee A (2014) Pharmacodynamic interaction of green tea extract with hydrochlorothiazide against cyclophosphamide-induced myocardial damage. Toxicol Int 21:196-202 
26. Zhang J, Knapton A, Lipshultz SE, Weaver JL, Herman EH (2008) Isoproterenol-induced cardiotoxicity in Spraque-Dawley rats: correlation of reversible and irreversible myocardial injury with release of cardiac troponin T and roles of iNOS in myocardial injury. Toxicol Pathol 36:277-278

27. Baldissera MD, Souza CF, Grando TH, Stefani LM, Monteiro SG (2017) $\beta$ caryophyllene reduces atherogenic index and coronary risk index in hypercholesterolemic rats: the involvement of cardiac oxidative damage. Chem Biol Interact 270:9-14

28. Bhatt L, Joshi V (2017) Mangifera indica L. leaf extract alleviates doxorubicin induced cardiac stress. J Intercult Ethnopharmacol 6:284

29. Wexler BC (1978) Myocardial infarction in young vs old male rats: pathophysiologic changes. Am Heart J 96:70-80

30. Ahmad U, Ahmad RS, Arshad MS, Mushtaq Z, Hussain SM, Hameed A (2018) Antihyperlipidemic efficacy of aqueous extract of Stevia rebaudiana Bertoni in albino rats. Lipids Health Dis https://doi.org/10.1186/s12944-018-0810-9

31. Brahmachari G, Mandal LC, Roy R, Mondal S, Brahmachari AK (2011) Stevioside and related compounds - molecules of pharmaceutical promise: a critical overview. Arch Pharm (Weinheim) 344:5-19

32. Kela AK, Reddy LP, Thombre DP E.C.G. findings in normal rats and after administration of isoproterenol. Indian J Physiol Pharmacol 24:84-90

33. Patel $\mathrm{S}$, Bhatt L, Patel R, Shah C, Patel V, Patel J, Sundar R, Bhatnagar U, Jain M (2017) Identification of appropriate QTc formula in beagle dogs for nonclinical safety assessment. Regul Toxicol Pharmacol 89:118-124

34. Shah C, Bhatt L, Ravichandra BV et al (2019) Influence of estrous stages on electrocardiography, clinical pathology and ovarian weight of experimental beagle dogs: a retrospective analysis. Interdiscip Toxicol 12:149-156

35. Barman NR, Nandy S, Datta R, Kar PK (2013) Cardioprotective effect of ethanolic extract of Urtica parviflora Roxb. against isoproterenol induced myocardial infarction in rats. Indian J Pharm 45:513-516

36. Sirotković-Skerlev M, Plestina S, Bilić I, Kovac Z (2006) Pathophysiology of ischaemia-reperfusion injury. Lijec Vjesn 128:87-95

\section{Publisher's Note}

Springer Nature remains neutral with regard to jurisdictional claims in published maps and institutional affiliations.

\section{Submit your manuscript to a SpringerOpen ${ }^{\circ}$ journal and benefit from:}

- Convenient online submission

- Rigorous peer review

- Open access: articles freely available online

High visibility within the field

- Retaining the copyright to your article

Submit your next manuscript at $\gg$ springeropen.com 